\title{
Root-endophytic fungi cause morphological and functional differences in Scots pine roots in contrast to ectomycorrhizal fungi
}

\begin{tabular}{|r|l|}
\hline Journal: & Botany \\
\hline Manuscript ID & cjb-2016-0161.R1 \\
\hline Manuscript Type: & Note \\
\hline Date Submitted by the Author: & 05-Sep-2016 \\
\hline Complete List of Authors: & $\begin{array}{l}\text { Heinonsalo, Jussi; Helsingin Yliopisto Maatalous-Metsatieteellinen } \\
\text { Tiedekunta, Food and Environmental Sciences } \\
\text { Buée, Marc; Centre INRA de Nancy } \\
\text { Vaario, Lu-Min; Luonnonvarakeskus }\end{array}$ \\
\hline Keyword: & endophytic fungi, root, enzyme, pine, functional trait \\
\hline & \\
\hline
\end{tabular}

\section{SCHOLARONE ${ }^{\text {m }}$}

Manuscripts 


\section{Root-endophytic fungi cause morphological and functional}

\section{2 differences in Scots pine roots in contrast to}

\section{3 ectomycorrhizal fungi}

4

5 Heinonsalo $^{1 *}$, Jussi, Buée ${ }^{2,3}$, Marc, and Vaario ${ }^{4}$, Lu-Min

6

$7{ }^{1}$ Viikki Biocenter, Department of Food and Environmental Sciences, Faculty of Agriculture

8 and Forestry, P.O. Box 56, FIN-00014, University of Helsinki, Helsinki, Finland, tel. +358-

92941 59317, email: jussi.heinonsalo@helsinki.fi

$10{ }^{2}$ INRA, UMR1136 Interactions Arbres-Microorganismes, F-54280 Champenoux, France ;

11 Université de Lorraine, UMR1136 Interactions Arbres-Microorganismes, F-54500

12 Vandoeuvre-lès-Nancy, France, email: buee@nancy.inra.fr

$13{ }^{4}$ Natural Resources Institute Finland, PL 18, FI-01301 Vantaa, Finland, email : lu-

14 min.vaario@luke.fi ${ }^{1}$

15

$16 *=$ corresponding author

\footnotetext{
${ }^{1}$ Current address, The University of Tokyo, Mitori machi 1-1-8, Tokyo, Japan, lumin_vaario@yahoo.com
} 


\section{Abstract}

2 Endophytic fungi and ectomycorrhizal fungi co-exist in the mycorrhizal root tips of boreal

3 forest trees. However, very little is known about the functional role they play in their host's

4 biology. The activity of enzymes responsible for important biochemical processes is used to

5 unravel the functional role of root-associated mycorrhizal fungi. However, enzyme activity is

6 never studied in the presence of endophytic fungi in planta. The aims of the present study

7 were to investigate the effect of Scots pine root-isolated fungal endophytes on the host plant

8 root morphology, to determine their functional effect using host root-excreted enzyme activity

9 measurements and to compare them to roots colonized by decomposer and ectomycorrhizal

10 fungal strains and non-colonised Scots pine root tips. Our results show that endophytic fungi

11 did not damage the pine roots in contrast to the decomposer fungi. The endophytic fungi

12 penetrated the cortical cells of the host plant. The roots colonised by endophytic fungi

13 produce different exo-enzymes compared to those produced by roots colonized by other

14 fungal groups or non-colonized control root tips. Our results indicate that endophytic fungi

15 are clearly a distinctive ecological group of fungi that have functional traits different from

16 those of ectomycorrhizal and decomposer fungi.

17

18
Keywords: endophytic fungi, root morphology, enzyme, functional trait, pine 


\section{Introduction}

2 Plant roots contain a wide range of fungal endophytes (Vandenkoonhuyse et al. 2002; Addy et

3 al. 2005; Mandyam and Jumpponen 2005). Recent research on root-associated fungi has

4 focused on symbiotic mycorrhizal fungi, which were shown to play a crucial role in plant

5 performance in many different ecosystems (Van der Heijden et al. 1998; Smith and Read

6 2008). However, a large part of the root-associated fungi is endophytic, but not mycorrhizal

7 (Rodriguez et al. 2009). These endophytic fungi inhabit the root tissue but do not form

8 cellular interfaces with the plant partner using specialized structures (Rodriguez et al. 2009).

9 Such endophytic associations may be parasitic, saprotrophic, mutualistic, or neutral.

10 However, the ecological status of the association between the endophytic fungi and the host

11 plant is often unclear. The most studied root endophytes, the so called dark septate endophytes (DSE), were earlier suggested to be functionally similar to symbiotic mycorrhizal fungi (Jumpponen 2001). However, DSEs are recently defined as 'not causing negative

14 effects on plant performance' (Newsham et al. 2011), and may sometimes form symbiotic structures like mycorrhizal fungi (Lukesova et al. 2015). Today, the definition of the DSE still suffers from lack of taxonomic cohesion, the polyphyletic evolutionary origins of these fungi

17 and their variable ecological or physiological functions (Mandyam and Jumpponen 2014).

Root-inhabiting fungi other than DSEs are even less well studied, and their ecology is poorly

19 understood. The global diversity, abundance and functional roles of these root-colonising

20 fungi are also largely unknown (Addy et al. 2005; Mandyam and Jumpponen 2005) despite

21 their presence in roots being known for more than 100 years and reported in thousands of

22 scientific articles (Rodriquez et al. 2009).

23 Root endophytes are most commonly identified by direct agar plate culturing after surface 24 sterilization of roots. The identity of uncultured root endophytes may also be determined by 25 extracting DNA from the surface-sterilized roots. However, the PCR-amplification of the 
1 internal transcribed spacer (ITS) region for example, may also amplify DNA from dead

2 fungal endophytes or epiphytic fungi found on the surface of the roots. Therefore, despite

3 advances in the development of molecular biological tools, the isolation of pure cultures of

4 root endophytes is invaluable when the targeted species is cultivable. It is possible to

5 determine their physiological properties and host effect of root endophytes only with pure

6 cultured endophytic fungal strains.

7 An abundance of endophytic fungi in the roots of woody plant species like Scots pine (Pinus

8 sylvestris, L.) is commonly observed (Sieber and Grünig 2013). Endophytic fungi also co-

9 exist with ectomycorrhizal (ECM) fungi in mycorrhizal root tips of boreal forest trees

10 (Kernaghan and Patriquin 2011; Reininger and Sieber 2012). The role and function of

11 endophytes within mycorrhizas is not properly understood. Attempts to isolate pure cultures

12 of mycorrhizal fungi often lead to the co-isolation of endophytic fungi (e.g. Uroz and

13 Heinonsalo 2008).

14 Enzyme activity measurements have been used to estimate the capacity of soil microbial

15 communities to maintain functional diversity because specific enzymes drive most of the

16 biochemical reactions in soil (Caldwell, 2005; Talbot et al. 2014). Similarly, enzyme activity

17 measurements of tree root tips colonized by ectomycorrhizal fungi are used as a tool for

18 studying the functional diversity of ECM communities (Courty et al. 2005). The combination

19 of six functional markers (enzyme assays) allowed the classification of 26 fungal strains into

20 groups that include white, soft rot and brown rot fungi (Mathieu et al. 2013). The recently

21 developed fungal guild classification predicts the enzymatic role of fungi and links fungal

22 guilds to soil biogeochemical processes based on a combination of enzyme activity data,

23 biomass data and molecular and functional gene data (Talbot et al. 2015). Enzyme activity

24 measurements of host root-inoculated endophytic fungi has never been performed despite the 
1 fact that enzyme activity profiling may produce significant new knowledge on the largely

2 unknown functional roles of such endophytic fungi.

3 The first aim of the study was to investigate the association between eight root-isolated fungal

4 strains and Scots pine roots using root section microscopy. The second and main aim was to

5 study how these strains affect the secreted enzymes pattern of fungal-inoculated roots (Pritsch

6 et al. 2004; Courty et al. 2005; Pritsch et al. 2011). The study includes the isolation of two

7 ectomycorrhizal fungi, three endophytic fungi and three decomposer (later 'decay') fungi. We

8 hypothesize that 1) fungal colonisation within plant roots alters the root morphology and the

9 root-excreted enzyme activities and, 2) the endophytic fungi can be grouped into different ecological groups (fungal guilds) based on functional analysis of fungi in interaction with

11 pine root, based on their enzyme activity profiles, and 3) ectomycorrhizal and endophytic

12 fungi have more similar enzyme activity profiles than decay fungi, which supports the

13 hypothesis that endophytic fungi have a mutualistic association with the host plant, supporting

14 neutral or positive effects on plant performance.

15

16

\section{Materials and methods}

Seedling establishment, fungal strains, inoculation and growth conditions

Scots pine (Pinus sylvestris L.) seeds were surface-sterilized and germinated on glucose agar.

Sterile germinated seeds were transferred to $20 \mathrm{~mm}$ diameter test tubes where they were grown until the first lateral short roots emerged after approximately three weeks. The seedlings $(\mathrm{N}=3)$ were inoculated with eight fungal strains (Table 1), selected to represent ectomycorrhizal (ECM), endophytic (ENDO) and decomposer (DECAY) fungi. The protocol for the fungal isolation is explained in details in Bäck et al. (2010). Non-inoculated seedlings were included as controls (CON). The seedlings were grown under stable growth conditions 
1 (temperature $+20^{\circ} \mathrm{C}$, irradiation $200 \mu \mathrm{mol} \mathrm{m} \mathrm{m}^{-2}$ and day/night cycle of $18 / 6 \mathrm{~h}$ ) for three

2 months (Heinonsalo et al. 2015) until harvested for microscopic, enzymatic and biomass

3 analyses.

4 The strains were all originally isolated in Finland from Scots pine ectomycorrhiza except for

5 the litter-decomposing fungal strain, which was isolated from a Collybia dryophila fruiting

6 body. The taxonomic identity of the nine strains was determined by sequencing the ITS

7 region of the rRNA operon using the ITS1 and ITS4 primer pair (Gardes and Bruns 1993).

8 The sequences were deposited in GenBank and their accession numbers are given in Table 1.

9 The strains were deposited as pure cultures in the Fungal Biotechnology Culture Collection

10 (FBCC within HAMBI) at the University of Helsinki, Finland.

\section{Root sections and microscopy}

13 Seven root tips were randomly selected from the root system of inoculated and non-inoculated

14 seedlings $(\mathrm{N}=3)$ and were prepared for microscopy by pre-fixing them at $+4{ }^{\circ} \mathrm{C}$ overnight in

$150.1 \mathrm{M}$ phosphate buffer ( $\mathrm{pH} 7.0)$ containing $2.5 \%(\mathrm{v} / \mathrm{v})$ glutaraldehyde. Subsequently, the root tips were rinsed three times for 10 min with phosphate buffer $\left(\mathrm{pH} \mathrm{7.0)}\right.$ at $+4{ }^{\circ} \mathrm{C}$, followed

17 by a fixing period of 3-4 hours in $1 \%$ osmium tetroxide $\left(\mathrm{OsO}_{4}\right)$ phosphate buffer $(\mathrm{pH} 7.0)$.

18 The samples were dehydrated after rinsing three times for $10 \mathrm{~min}$ with phosphate buffer $(\mathrm{pH}$

197.0 ) at $+4{ }^{\circ} \mathrm{C}$. The samples were soaked twice in $50 \%$ ethanol, then in $70 \%, 94 \%, 100 \%$

20 ethanol and finally in $2 \%$ uranyl acetate in $100 \%$ ethanol for $10 \mathrm{~min}$ each. The samples were

21 treated three times in propylene oxide for $10 \mathrm{~min}$ at $+20^{\circ} \mathrm{C}$ before eponification. Samples

22 were incubated for 60 min in 3:1 mixture of propylene oxide and Epon resin (Ladd LX 112).

23 The samples were then incubated for $120 \mathrm{~min}$ in 1:1 mixture of propylene oxide and Epon

24 resin, $120 \min$ in 1:3 mixture and finally in pure Epon resin overnight. The samples were 
1 placed in pure Epon at $+20^{\circ} \mathrm{C}$ prior to polymerization for one day at $+37^{\circ} \mathrm{C}$ and three days at $2+60^{\circ} \mathrm{C}$.

3 One $\mu \mathrm{m}$ sections were cut and stained with $0.1 \%$ toluidine blue for 30 min before examination

4 with a Leica DMLB microscope (Leica ${ }^{\circledR}$, Wetzlar, Germany). Microscope section

5 photographs taken with a Zeiss Microscope with ZEN2012 blue edition software (Carl Zeiss

6 Microscopy $\mathrm{GmbH}$ ) were used to analyze the host-effect of fungal isolates.

7

$8 \quad$ Enzyme assays

The seven randomly selected root tips cut earlier from the roots of inoculated and noninoculated seedlings for root sections were also used for the enzyme assays, as described in Courty et al. (2005). Seven of the enzyme assays performed were based on fluorescent detection of 4-methylumbelliferone (MU) or 7-amino-4-methylcoumarin (AMC) substrates and one on photometric detection of 2,2'-azinobis-3-ethylbenzothiazoline-6-sulfonate (ABTS) reaction products. The enzymes and corresponding substrates studied were acid phosphatase (EC 3.1.3.2; MU-phosphate), $\beta$-glucosidase (EC 3.2.1.3; MU- $\beta$-D-glucopyranoside), Nacetyl-glucosaminidase (EC 3.2.1.14; MU-N-acetyl- $\beta$-D-glucosaminide), glucuronidase, (EC 3.2.1.31; MU- $\beta$-D-glucuronide hydrate), xylosidase (EC 3.2.1.37; MU- $\beta$-D-xylopyranoside ), cellobiohydrolase (EC 3.2.1.91; MU- $\beta$-D-cellobioside ), leucine aminopeptidase (EC 3.4.11.1; L-leucine-AMC ) and laccase (EC 1.10.3.2; ABTS). The enzyme activities are expressed as pmol $\mathrm{min}^{-1} \mathrm{~mm}^{-2}$. The surface area of the analysed root tips was estimated using WinRhizo $^{\text {TM }}$ program (Regent Instruments, Quebec, Canada) and the results were calculated as previously described (Pritsch et al. 2011). 
1 Total biomass was measured after collection of the root tips for the microscopic and enzyme

2 assays. Total nitrogen and carbon content of the shoots was determined from dried and

3 ground samples by using a varioMAX CN analyzer (Elementar Analysensysteme GmbH,

4 Hanau, Germany). Shoots weighing less than $50 \mathrm{mg}$ DW were omitted from the $\mathrm{N}$ analysis

5 because the total $\mathrm{N}$ measurement is sensitive to small samples.

\section{$7 \quad$ Statistical analysis}

8 The effects of different fungal treatments on enzyme activities and biomass were tested using

9 one-way analysis of variance (ANOVA) followed by the Tukey post hoc test. The non-

10 parametric Kruskal-Wallis test was used when assumptions of normality or equality of

11 variances were not met. ANOVA and non-parametric tests were performed using IBM SPSS

12 Statistics version 23.0.0.2. Endophytic, ectomycorrhizal and decay fungal colonised root tips

13 were compared to control roots using a distance-based linear discriminant analysis (LDA)

14 with fungal functional groups as grouping factor in order to investigate the multivariate

15 patterns of enzyme activities (RStudio, Inc, Version 0.99.491, package MASS). The

16 differences in the DA1 and DA2 axis scores in different functional groups were tested using

17 ANOVA as described above.

\section{Results}

20 Effect of fungal inoculation on root structures

21 The effect of fungal inoculation on root structures was examined using light microscopy (Fig.

22 1). Non-inoculated Scots pine control root tips were intact (Fig. 1-A) and are used as a

23 reference for fungal-inoculated root sections. The roots remained healthy after inoculation

24 with the ECM fungi Tomentelloposis echinospora or Suillus variegatus. Multiseriate hyphae

25 surrounded the root surface and formed a mantle in seedlings inoculated with T. echinospora 
1 (Fig. 1-B). The root surface of seedlings inoculated with Suillus variegatus displayed only a

2 thin mantle structure (Fig. 1-C). Well-developed Hartig net structures were observed

3 throughout the cortex in both sets of seedlings, confirming the formation of ECM associations

4 (Fig. $1 \mathrm{~B}, \mathrm{C})$.

5 The root section of seedlings inoculated with the endophyte Phialocephala fortinii displayed a

6 thin layer of hyphae surrounding the root surface, and massive colonization by intercellular

7 and intracellular hyphae were found in both cortical and cortex cells. The hyphae present in

8 cortical cells formed coils and a deeply stained layer of tannin cells was also observed (Fig. 1-

9 D). Intracellular hyphal coils were also observed in root sections of the endophytes

Metapochonia bulbillosa and Meliniomyces variabilis (Fig. 1-E, F). However, the presence of

11 clear intercellular hyphae, a tannin cell layer and the initial Hartig net-like structure was also

12 observed in cortical layer in the sections of Meliniomyces variabilis (Fig. 1-F).

14 The root tissues of the seedlings inoculated with the decay fungi Sistotrema brinkmannii,

15 Conichaeta ligninaria and Gymnopilus penetrans were clearly collapsed (Fig. 1-G, H, I) and

16 the same signs of damage and empty cells were also observed in the roots of seedlings

17 inoculated with the litter-decomposing Collybia dryophila (Fig. 1-J).

\section{Enzyme activities}

20 The catalytic activity for each enzyme assayed, and the sum of all enzyme activities per

21 treatment are given in Table 2. The large variation in the measured enzyme activities between

22 individual root tips resulted in just a few statistically significant differences between the

23 treatments. Significant differences were observed in xylosidase, cellobiohydrolase, $\beta$ -

24 glucosidase and "chitinase" (N-acetyl-glucosaminidase) treatments. The sum of all enzyme

25 activities differed significantly between the treatments (Table 2). No statistically significant 
1 differences were observed for glucuronidase, acid phosphatase, leucine aminopeptidase and

2 laccase enzyme activities. The non-fungal control seedlings usually had the lowest enzyme

3 activities while seedlings inoculated with the endophytic $P$. fortinii had the highest activities.

4

5 The enzyme data analysed using linear discriminant analysis (LDA) showed that

6 ectomycorrhizal and endophytic fungal clusters were the most distant from each other while

7 controls and decay fungi fell in between these groups (Fig 2). The endophytic fungi differed

8 significantly from all other groups while ectomycorrhiza differed from decay fungi but not

9 from control according to the first discriminant axis (DA) that explained $78 \%$ of the variation

10 in the data (Table 3). The control seedlings differed from all fungal inoculated seedlings

11 according to the second DA that explained $22 \%$ of the variation in the data (Table 3 ).

\section{Seedling performance and fungal effect on host roots}

14 The shoot, root or total biomass or the roots/shoot ratio did not differ significantly between

15 the seedlings in different inoculation or control treatments. The average shoot biomass was 0.16-0.33 g DW, root biomass 0.21-0.81 g DW, total biomass 0.40-1.08 g DW, root/shoot

17 ratio 1.15-3.56 and needle nitrogen percentage 1.12-1.42 (data not shown).

\section{Discussion}

20 The ecological and functional role of most non-mycorrhizal root-inhabiting fungi is poorly

21 understood. There are indications that these endophytic fungi have mutualistic, parasitic,

22 pathogenic or neutral effects on the host plant (reviewed by Jumpponen et al. 1998, Mandyam

23 and Jumpponen 2005). It is often assumed that the presence of endophytic fungi is beneficial

24 to the host plant because the endophytic fungi often co-exist with ectomycorrhizal fungi in

25 apparently healthy roots (Kernaghan and Patriquin 2011) or that the co-colonization may even 
1 promote plant growth (Reininger and Sieber, 2013). The aim of this study was to investigate

2 the morphological features and functional role of root-inhabiting fungi in axenic conditions in

3 the roots of their original Scots pine host. The effect of endophytic fungi on root-excreted

4 enzyme activities has not been previously studied.

5 The inoculated fungi had a clear effect on host root morphology and confirmed the predefined

6 fungal guild classification. The control and ectomycorrhizal roots were healthy and

7 undamaged with no intracellular hyphal penetration, whereas most decay fungi inflicted

8 serious damage on the root tissues and cell structures. The intracellular colonisation by the

9 endophytic fungi resulted in minimal damage to the host tissue and healthy root tissue

structures were observed. The presence of endophytes was associated with a thickening of the

11 cell wall and structures within or between cortical cells based on examination of the root

12 section images. This was particularly clear for $P$. fortinii where there was an increased

13 amount of dense material, similar to the 'electron opaque material' previously reported

14 (Peterson et al. 2008), between the outer cortical cells. The intracellular colonization by $P$.

15 fortinii was denser and more abundant than that of the two other endophytes, Metapochonia

bulbillosa and Meliniomyces variabilis. A putative Hartig-net-like structure was observed in

17 the root tips, which were colonized by Melinomyces variabilis. This finding is inconsistent

with previous reports where Melinomyces variabilis modified the morphology of fine root tips

19 in a manner resembling early-stages of ectomycorrhizal development, but did not form typical

20 ectomycorrhizal structures, e.g. a mantle or a Hartig-net (Vohnik et al. 2007). Melinomyces

21 variabilis has been found to also colonize spruce root tip cortex (Vohnik et al. 2013). Our

22 findings suggest that endophytes like Melinomyces variabilis may have a flexible life-style

23 and lie at the crossroad between endophytism and mycorrhizal symbiosis.

24 The multi-enzyme assay, which was used for the first time in our study to investigate the

25 functioning of endophytic fungi, is widely used to study the functioning of ectomycorrhiza in 
1 forest soils (Pritsch et al. 2004; Courty et al. 2005; Pritsch et al. 2011). The assay has been

2 shown to detect mainly fungal exo-enzyme activities that are stable enough to allow transport

3 of root samples from the field, for processing and analysis in the laboratory (Pritsch et al.

4 2011). We used the same assay in a novel way in order to detect the effect of non-mycorrhizal

5 root-inhabiting fungi on enzyme production in association with original host plant roots and

6 compare them to activities of non-colonised and mycorrhizal root tips. Our results

7 demonstrate surprisingly small differences in the root-excreted enzyme activities between

8 Scots pine roots colonised by different kinds of fungi that are supposed to be functionally

9 very different. Sterile Scots pine had the lowest activities in most cases. However, due to the large variation between individual root tips, the enzyme activities induced by many of the

11 fungi did not differ from each other significantly. Our results indicate that all fungi inhabiting

12 the roots influenced the exo-enzymes produced by the plant-root association during our study

13 period. Furthermore, this result suggests that fungi primarily expressed or induced plants to

14 produce these exo-enzymes. Only the phosphatase enzyme appears to be expressed at similar

15 levels by the plant. Moreover, the roots colonized by the endophytic fungus $P$. fortinii had

16 very high enzymatic activities in comparison to the other fungal strains. These high levels of

17 activities could be related to the high density of $P$. fortinii hyphae within and around pine

18 roots as illustrated in our microscopic observations. Significant fungal species-related

19 differences in hemicellulase, cellulase and chitinase enzymatic activities, which are all

20 involved in cell-wall degradation, but not with other enzymes, were found among the fungi

21 tested. However, it is important to note that this assay does not provide any proof of nutrient

22 transfer from the fungal partner to the host, which is often the case in mycorrhizal symbiosis.

23 It is also noteworthy that the timing of the analysis may play a role as the plant-fungal

24 interaction may form a continuum along a gradient from mutualism to commensalism and to

25 parasitism (Peterson et al. 2008). Therefore, we conclude that the activities detected in the 
1 root tip analysis must be interpreted with caution, if the functional role of root-associated

2 fungi is not known and the benefits to the host plant are uncertain.

3 Despite few significant differences in the activities of individual enzymes, the multivariate

4 discriminant analysis showed a separation between ectomycorrhizal, endophytic and decay

5 fungi when the score of the first discriminant axis was considered. The first axis explained

$678 \%$ of the variation in the data. The second axis separated enzyme patterns of non-inoculated

7 root tips from all fungal-inoculated root tips. This is an important finding and shows that

8 endophytic fungi induce different enzymatic reactions in host plants compared to

9 ectomycorrhizal and decay fungi. Interestingly, Mathieu et al. (2013) used similar enzymatic

10 activity measurements and validated these functional traits to separate fungal ecological

11 groups within decaying fungi.

13 The biomass of the plants subjected to different treatments was not statistically different.

14 Differences in biomass were not expected as the aim of the experiment was to obtain active

15 and living root tips for root sectioning and enzyme activity analysis. Therefore the duration of

16 the experimental period compared to total plant growth period was intentionally short, which

17 resulted in only small changes in biomass. More seedlings would have probably become

18 unhealthy or died in this laboratory growth environment had a longer experimental period

19 been used and it would not have been possible to conduct the functional assay.

\section{Conclusions}

22 The root-isolated fungi included in this study clearly had different structures around or within 23 root tissues of the host plant. The non-inoculated control and ectomycorrhizal seedlings had

24 healthy-looking roots with intact cells, whereas endophytic fungi had intracellular penetration 25 and structures. The decay fungi tested damaged the root structures as expected. Our data 
1 suggests that all fungi colonising the roots of the Scots pine plants change the rhizobiome

2 enzymatic pattern and that measured activities of exo-enzymes do not prove that the enzyme

3 exudation is beneficial to the plant. The enzyme activity pattern detected in root tip analysis

4 did not correlate with the root morphological characteristics of the seedling suggesting that

5 root tip exo-enzyme analysis is not suitable for assessing endophyte-plant nutrient transfer

6 patterns. Our results show for the first time that endophytic fungi have a different enzyme

7 activity pattern in roots compared to ectomycorrhizal and decay fungi. In particular, it seems

8 that $P$. fortinii significantly increases the production of enzymes in root tips but the

9 consequences of this increased activity for the host plant are not clear. Our results do not support the hypothesis that endophytic and mycorrhizal fungi have similar effects on the host

11 plant. Our results indicate instead that endophytic fungi are clearly a distinctive ecological

12 group of fungi that have typical functional characteristics, different from those of

13 ectomycorrhizal and decay fungi.

14

\section{Acknowledgements}

16 We thank Dr. Karoliina Niemi for advice on root sample fixation. This research was

17 supported by grants from the Academy of Finland (project grants 263858 and 292699).

19 References

20 Addy, H.D., Piercey, M.M., and Currah, R.S. 2005. Microfungal endophytes in roots. Can. J.

21 Bot. 83: 1-13. doi: 10.1139/B04-171

22 Bäck, J., Aaltonen, H., Hellén, H., Kajos, M.K., Patokoski, J., Taipale, R., et al. 2010.

23 Variable emissions of microbial volatile organic compounds (MVOCs) from root-associated

24 fungi isolated from Scots pine. Atmosph. Environ. 44: 3651-3659. doi:

$25 \quad 10.1016 /$ j.atmosenv.2010.06.042 
1 Caldwell, B.A. 2005. Enzyme activities as a component of soil biodiversity: A review.

2 Pedobiologia 49: 637-644. doi:10.1016/j.pedobi.2005.06.003

3 Courty, P.-E., Pritsch, K., Schloter, M., Hartmann, A., and Garbaye, J. 2005. Activity

4 profiling of ectomycorrhizal communities in two forest soils using multiple enzymatic tests.

$5 \quad$ New Phytol. 167: 309-19. doi:10.1111/j.1469-8137.2005.01401.x

6 Gardes, M., and Bruns, T.D. 1993. ITS primers with enhanced specificity for basidiomycetes

7 - an application to the identification of mycorrhizae and rust. Mol. Ecol. 2: 113-118. doi:

$8 \quad 10.1111 /$ j.1365-294X.1993.tb00005.x

9 Heinonsalo, J., Juurola, E., Linden, A., and Pumpanen, J. 2015. Ectomycorrhizal fungi affect

10 Scots pine photosynthesis through nitrogen and water economy, not only through increased

11 carbon demand. Environ. Exp. Bot. 109: 103-112. doi: 10.1016/j.envexpbot.2014.08.008

12 Jumpponen, A., Mattson, K.G., and Trappe, J.M. 1998. Mycorrhizal functioning of

13 Phialocephala fortinii with Pinus contorta on glacier forefront soil: interactions with soil

14 nitrogen and organic matter. Mycorrhiza 7: 261-265. doi: 10.1007/s005720050190

15 Jumpponen, A. 2001. Dark septate endophytes - are they mycorrhizal? Mycorrhiza 11: 207-

16 211. doi: $10.1007 / \mathrm{s} 005720100112$

17 Kernaghan, G., and Patriquin, G. 2011. Host associations between fungal root endophytes and

18 boreal trees. Microb. Ecol. 62: 460-73. doi: 10.1007/s00248-011-9851-6.

19 Lukesova, T., Kohout, P., Vetrovsky, T., and Vohnik, M. 2015. The potential of Dark Septate

20 Endophytes to form root symbioses with ectomycorrhizal and ericoid mycorrhizal middle

21 European forest plants. PLoS ONE 10(4): e0124752. doi: 10.1371/journal.pone.0124752

22 Mandyam, K., and Jumpponen, A. 2005. Seeking the elusive function of the root-colonising

23 dark septate endophytic fungi. Stud. Mycol. 53: 173-189. doi: 10.3114/sim.53.1.173

24 Mandyam, K.G., and Jumpponen, A. 2014. Mutualism-parasitism paradigm synthesized from

25 results of root-endophyte models. Front. Microbiol. 5: 776. doi: 10.3389/fmicb.2014.00776 
1 Mathieu, Y., Gelhaye, E., Dumarçay, S., Gérardin, P., Harvengt, L., and Buée, M. 2013.

2 Selection and validation of enzymatic activities as functional markers in wood biotechnology

3 and fungal ecology. J. Microbiol. Met. 92: 157-163. doi: 10.1016/j.mimet.2012.11.017

4 Newsham, K. K. 2011. A meta-analysis of plant responses to dark septate root endophytes.

$5 \quad$ New Phytol. 190: 783-793. doi: 10.1111/j.1469-8137.2010.03611.x

6 Peterson, R.L., Wagg, C., and Pautler, M. 2008. Associations between microfungal

7 endophytes and roots: do structural features indicate function? Botany 86: 445-456. doi:

$8 \quad 10.1139 / B 08-016$

9 Pritsch, K., Raidl, S., Marksteiner, E., Blaschke, H., Agerer, R., Schloter, M., et al. 2004. A

10 rapid and highly sensitive method for measuring enzyme activities on single mycorrhizal tips

11 using 4-methylumbelliferone-labelled fluorogenic substrates in a microplate system. J.

12 Microb. Met. 58: 233-241. doi: 10.1016/j.mimet.2004.04.001

13 Pritsch, K., Courty, P., Churin, J.-L., Cloutier-Hurteau, B., Ali, M., Damon, C., et al. 2011.

14 Optimized assay and storage conditions for enzyme activity profiling of ectomycorrhizae.

15 Mycorrhiza 21: 589-600. doi: 10.1007/s00572-011-0364-4

16 Reininger, V., and Sieber, T.N. 2012. Mycorrhiza reduces adverse effects of Dark Septate

17 Endophytes (DSE) on growth of conifers. PLoS ONE 7(8): e42865. doi:

18 10.1371/journal.pone.0042865

19 Reininger, V., and Sieber, T.N. 2013. Mitigation of antagonistic effects on plant growth due

20 to root co-colonization by dark septate endophyte and ectomycorrhizal. Environ. Microbiol.

21 Rep. 5(6): 892-898. doi: 10.1111/1758-2229,12091

22 Rodriguez, R.J., White, J.F. Jr., Arnold, A.E., and Redman, R.S. 2009. Fungal endophytes:

23 diversity and functional roles. New Phytol. 182: 314-330. doi: 10.1111/j.1469-

$24 \quad 8137.2009 .02773 . x$ 
1 Talbot, J.M., Bruns, T.D., Taylor, J.W. Smith, D.P., Branco, S., Glassman, S.I., et al. 2014.

2 Endemism and functional convergence across the North American soil mycobiome. PNAS,

3 111: 6341-6346. doi:10.1073/pnas.1402584111

4 Uroz, S., and Heinonsalo, J. 2008. Degradation of N -acyl homoserine lactone quorum

5 sensing signal molecules by forest root-associated fungi. FEMS Microbiol. Ecol. 65: 271-278.

6 doi: $10.1111 / \mathrm{j} .1574-6941.2008 .00477 . x$

7 Sieber, T.N., and Grünig, C.R. 2013. Fungal root endophytes. In: The Hidden Half, 4th edn.

8 Edited by Eshel, A. and Beeckman, T. 2013.Chapter 38: pages 38.31-38.49; CRC Press,

9 Taylor \& Francis Group, Boca Raton, FL, USA.

10 Smith, S.E., and Read, D.J. 2008. Mycorrhizal Symbiosis, third ed. Academic Press,

11 Cambridge, UK.

12 Vandenkoornhuyse, P., Baldauf, S.L., Leyval, C., Straczek, J., and Young, J.P.W. 2002.

13 Extensive fungal diversity in plant roots. Science 295: 2051 doi:

$14 \quad 10.1126 /$ science.295.5562.2051

15 Van der Heijden, M. G., Klironomos, J. N., Ursic, M., Moutoglis, P., Streitwolf-Engel, R., 16 Boller, T., et al. 1998. Mycorrhizal fungal diversity determines plant biodiversity, ecosystem 17 variability and productivity. Nature 396: 69-72. doi: 10.1038/23932

18 Vohnik, M., Fendrych, M., Albrechtová, J., and Vosátka, M. 2007. Intracellular colonization

19 of Rhododendron and Vaccinium roots by Cenococcum geophilum, Geomyces pannorum and 20 Meliniomyces variabilis. Folia Microbiol. 52: 407-414. doi: 10.1007/BF02932096

21 Vohnik, M., Mrnka, L., Lukešová, T., Bruzone, M. C., and Kohout, P. 2013. The cultivable 22 endophytic community of Norway spruce ectomycorrhizas from microhabitats lacking 23 ericaceous hosts is dominated by ericoid Meliniomyces variablis. Fungal Ecol. 6: 281-292. 24 doi: 10.1016/j.funeco.2013.03.006 
Table 1. Fungal strains used in this study and GenBank accession numbers for the ITS region of the ribosomal rRNA operon.

\begin{tabular}{|c|c|c|c|c|c|}
\hline Strain & Fungal species & $\begin{array}{l}\text { Collection } \\
\text { code }\end{array}$ & $\begin{array}{l}\text { Functional } \\
\text { group }\end{array}$ & Source of isolation & Accession no \\
\hline JH5 & Tomentellopsis echinospora & FBCC 1421 & Ectomycorrhizal & Scots pine mycorrhiza, Finland & LK052757 \\
\hline JH35 & Suillus variegatus & FBCC 1390 & Ectomycorrhizal & Scots pine mycorrhiza, Finland & FN556986 \\
\hline JH8 & Phialocephala fortinii & FBCC 1401 & Endophytic & Scots pine mycorrhiza, Finland & AM905084 \\
\hline JH19 & Metapochonia bulbillosa & FBCC 1400 & Endophytic & Scots pine mycorrhiza, Finland & AB378551* \\
\hline JH23 & Meliniomyces variabilis & FBCC 1402 & Endophytic & Scots pine mycorrhiza, Finland & AM905085 \\
\hline JH24 & Sistotrema brinkmannii & FBCC 1416 & Decomposer & Scots pine mycorrhiza, Finland & LK052763 \\
\hline JH37 & Coniochaeta ligniaria & FBCC 1417 & Decomposer & Scots pine mycorrhiza, Finland & LK052768 \\
\hline JH57 & Gymnopilus penetrans & FBCC 1415 & Decomposer & Scots pine mycorrhiza, Finland & AM905093 \\
\hline K209 & Collybia dryophila & FBCC 626 & Decomposer & Fruitbody, Finland & DQ068970 \\
\hline
\end{tabular}

*closest similarity 
Table 2. Enzyme activities measured in the root tips of control and fungal-inoculated seedlings (unit pmol $\mathrm{min}^{-1} \mathrm{~mm}^{-2}$ ). Mean values with different letters are significantly $(\mathrm{P}<0.05)$ different among the tested isolates.

\begin{tabular}{|c|c|c|c|c|c|c|c|c|c|c|c|c|c|c|c|c|c|c|c|}
\hline & & \multicolumn{2}{|c|}{ Glucuronidase } & \multicolumn{2}{|c|}{ Xylosidase } & \multicolumn{2}{|c|}{$\begin{array}{l}\text { Cellobio- } \\
\text { hydrolase }\end{array}$} & \multicolumn{2}{|c|}{ b-Glucosidase } & \multicolumn{2}{|c|}{ Chitinase } & \multicolumn{2}{|c|}{$\begin{array}{c}\text { Acid } \\
\text { phosphatase }\end{array}$} & \multicolumn{2}{|c|}{$\begin{array}{c}\text { Leucine } \\
\text { aminopeptidase }\end{array}$} & \multicolumn{2}{|c|}{ Laccase } & \multicolumn{2}{|c|}{$\begin{array}{c}\text { Sum of all enzyme } \\
\text { activities }\end{array}$} \\
\hline & & aver & stdev & aver & stdev & aver & stdev & aver & stdev & aver & stdev & aver & stdev & aver & stdev & aver & stdev & aver & stdev \\
\hline $\begin{array}{l}\text { Pine } \\
\text { control }\end{array}$ & CON & $0.00 a$ & 0.00 & $0.02 a b$ & 0.02 & $0.01 a$ & 0.01 & $0.04 a$ & 0.04 & $0.02 a$ & 0.05 & $1.73 a$ & 3.28 & $0.16 a$ & 0.07 & $0.05 a$ & 0.17 & $2.08 a$ & 3.35 \\
\hline JH5 & ECM & $0.01 a$ & 0.01 & $0.01 a b$ & 0.05 & $0.17 a b$ & 0.26 & $0.83 a b$ & 0.94 & $0.27 a b$ & 0.36 & $5.36 a$ & 7.66 & $0.35 a$ & 0.39 & $0.02 a$ & 0.03 & $7.05 a$ & 8.96 \\
\hline $\mathrm{JH} 35$ & ECM & $0.00 a$ & 0.00 & $0.00 a b$ & 0.05 & $0.33 a b$ & 0.35 & $0.90 a b$ & 0.90 & $1.67 a b$ & 1.51 & $2.92 a$ & 2.69 & $0.79 a$ & 0.53 & $0.05 a$ & 0.10 & $6.72 a$ & 5.15 \\
\hline $\mathrm{JH} 8$ & ENDO & $0.00 a$ & 0.029 & $1.41 \mathrm{~b}$ & 0.35 & $1.88 \mathrm{~b}$ & 0.38 & $4.18 b$ & 0.74 & $3.80 \mathrm{~b}$ & 0.88 & $4.03 a$ & 1.79 & $0.05 a$ & 0.03 & $0.06 a$ & 0.07 & $15.41 \mathrm{~b}$ & 3.26 \\
\hline $\mathrm{JH} 19$ & ENDO & $0.02 a$ & 0.00 & $0.05 a b$ & 0.021 & $0.12 a b$ & 0.08 & $0.79 a b$ & 0.58 & $0.22 \mathrm{ab}$ & 0.15 & $1.64 a$ & 0.46 & $0.09 a$ & 0.04 & $0.01 a$ & 0.02 & $2.94 a$ & 1.06 \\
\hline $\mathrm{JH} 23$ & ENDO & $0.04 a$ & 0.08 & $0.22 a b$ & 0.10 & $0.20 a b$ & 0.11 & $0.57 a b$ & 0.34 & $0.48 a b$ & 0.29 & $1.96 a$ & 0.88 & $0.06 a$ & 0.12 & $0.04 a$ & 0.04 & $3.58 a$ & 1.65 \\
\hline $\mathrm{JH} 24$ & DECAY & $0.00 a$ & 0.00 & $0.00 a$ & 0.01 & $0.02 a b$ & 0.02 & $0.39 a b$ & 0.15 & $0.31 a b$ & 0.16 & $0.86 a$ & 0.20 & $0.17 a$ & 0.07 & $0.02 a$ & 0.05 & $1.78 a$ & 0.29 \\
\hline JH37 & DECAY & $0.01 a$ & 0.00 & $0.05 a b$ & 0.03 & $0.23 a b$ & 0.38 & $0.98 a b$ & 1.02 & $0.12 a b$ & 0.06 & $2.09 a$ & 1.20 & $0.02 a$ & 0.04 & $0.01 a$ & 0.03 & $3.51 a$ & 2.57 \\
\hline JH57 & DECAY & $0.13 a$ & 0.08 & $0.12 \mathrm{ab}$ & 0.07 & $0.11 a b$ & 0.07 & $0.52 a b$ & 0.32 & 1.13ab & 1.02 & $6.03 a$ & 5.71 & $0.27 a$ & 0.19 & $0.06 a$ & 0.08 & $8.38 a b$ & 5.83 \\
\hline C.dry & DECAY & $0.05 a$ & 0.03 & $0.047 a b$ & 0.02 & $0.06 a b$ & 0.02 & $0.37 a b$ & 0.24 & $0.92 a b$ & 0.95 & $3.30 \mathrm{a}$ & 1.64 & $0.00 a$ & 0.00 & $0.02 \mathrm{a}$ & 0.21 & $4.82 a$ & 2.53 \\
\hline Statistic & test & JPAR & & NPAR & & NPAR & & NPAR & & NPAR & & NPAR & & NPAR & & NPAR & & ANOVA & \\
\hline
\end{tabular}


Table 3. The scores of discriminant axis 1 and 2 (DA1 and DA2) that explained $78 \%$ and $22 \%$ of the variation in linear discriminant analysis of enzyme activities respectively. Standard deviation is shown in brackets. $\mathrm{CON}=$ non-inoculated control pine, ECM= pine inoculated with ectomycorrhizal, ENDO= with endophytic and DECAY = with decomposer fungi. Different letter indicate statistical difference $(\mathrm{p}<0.05$, ANOVA).

\begin{tabular}{lcc} 
& DA1 & DA2 \\
\hline CON & $-0.72 \mathrm{ab}( \pm 1.69)$ & $1.80 \mathrm{a}( \pm 0.75)$ \\
ECM & $-2.34 \mathrm{a}( \pm 1.68)$ & $-0.57 \mathrm{~b}( \pm 1.15)$ \\
ENDO & $1.68 \mathrm{c}( \pm 0.91)$ & $-0.19 \mathrm{~b}( \pm 1.00)$ \\
DECAY & $-0.10 \mathrm{~b}( \pm 0.76)$ & $-0.07 \mathrm{~b}( \pm 0.98)$ \\
\hline
\end{tabular}




\section{Figure captions}

2 Figure 1. Root sections of non-colonised control and fungal-colonised Scots pine root tips.

3 Scale bar in images $20 \mu \mathrm{m}$ or $50 \mu \mathrm{m} . \mathrm{A}=$ Scots pine control, $\mathrm{B}=$ Tomentellopsis echinospora

4 ECM (JH5), C= Suillus variegatus ECM (JH35), D= Phialocephala fortinii ENDO (JH8), E=

5 Metapochonia bulbillosa ENDO (JH19), F= Meliniomyces variabilis ENDO (JH23), G=

6 Sistotrema brinkmannii DECAY (JH24), H= Coniochaeta ligninaria DECAY (JH37), I=

7 Gymnopilus penetrans DECAY (JH57), J= Collybia dryophila DECAY (K209)

8 Hyphae (h), Hyphal coil (hc), Tannin cells (tc), Hartig net (hn), putative Hartig net (phn),

9 Mantle (m).

10 Figure 2. Linear discriminant analysis plot analysed using enzyme activities and fungal

11 functional type as grouping factors. Discriminant axis DA1 and DA2 explains $78 \%$ and $22 \%$

12 of the variation respectively. $\mathrm{CON}=$ non-inoculated Scots pine root, $\mathrm{ECM}=$ ectomycorrhizal,

$13 \mathrm{ENDO}=$ endophytic and DECAY $=$ decomposer fungal colonised Scots pine root tips. 


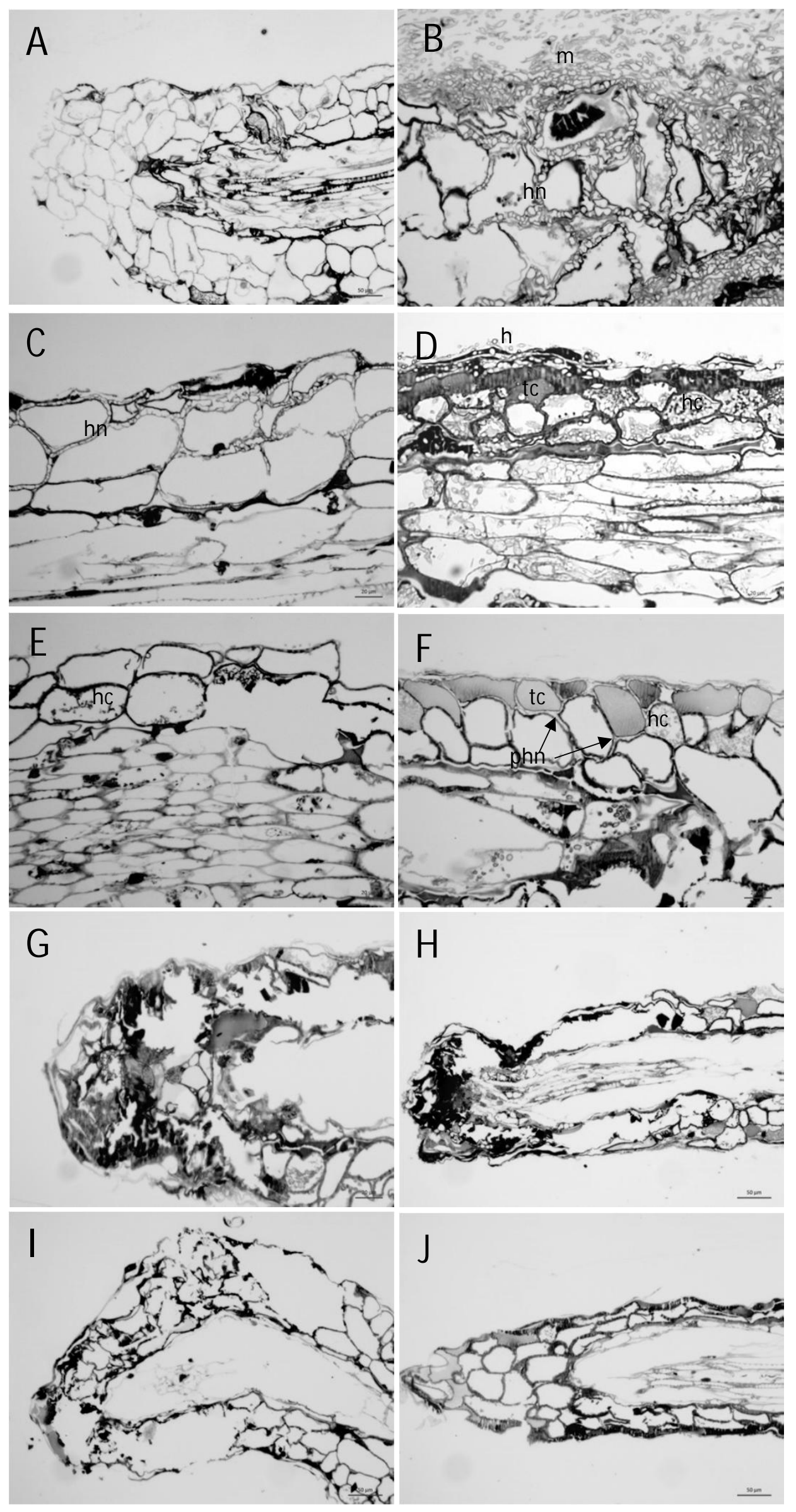




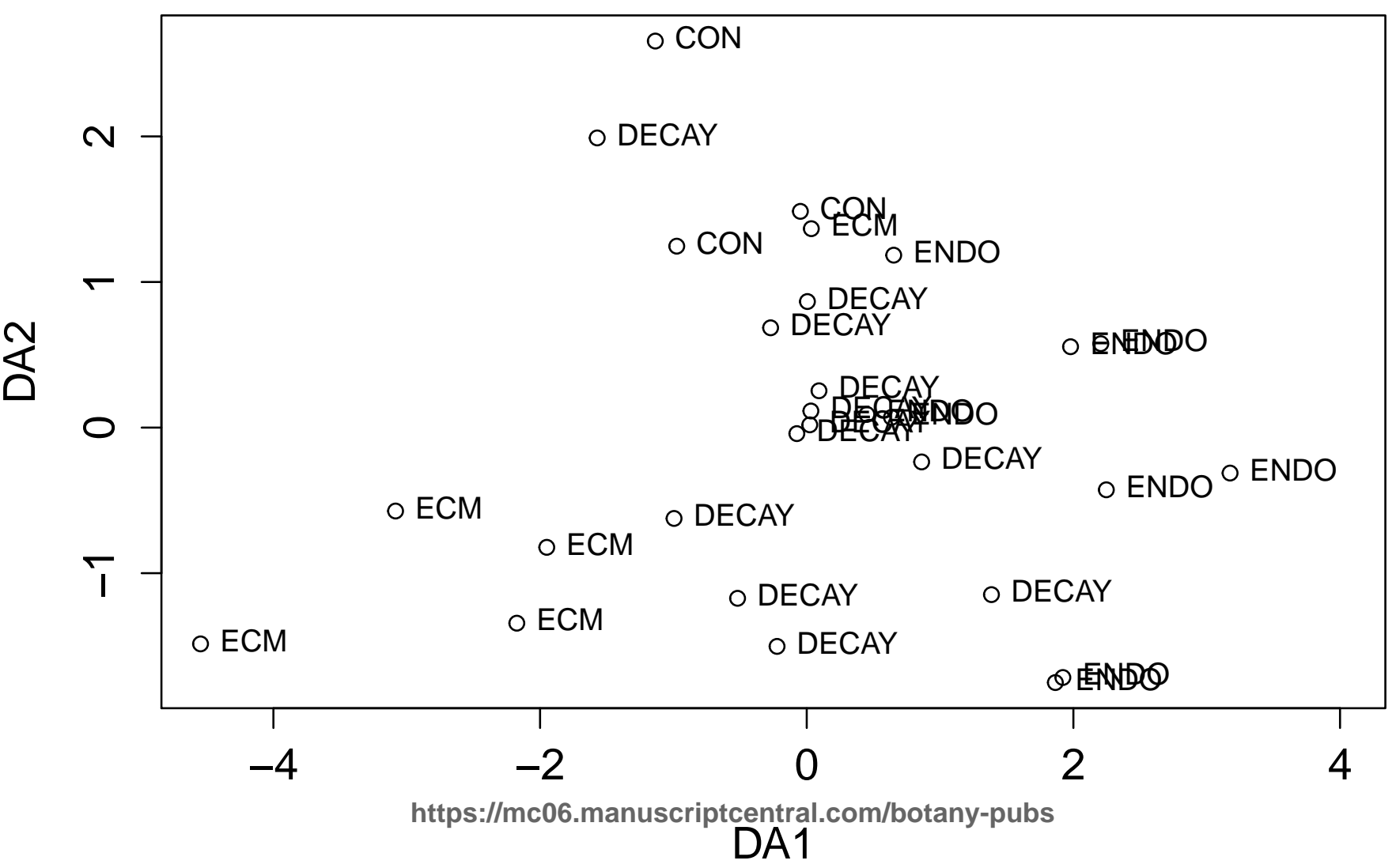

